\title{
Population structure of Actinobacillus actinomycetemcomitans: a framework for studies of disease-associated properties
}

\author{
Knud Poulsen, ${ }^{1}$ Else Theilade, ${ }^{2}$ Edward T. Lally, ${ }^{3}$ Donald R. Demuth ${ }^{4}$ and \\ Mogens Kilian'
}

Author for correspondence: Mogens Kilian. Tel: +45 89421735. Fax: +4586196128.

\author{
1,2 Institute of Medical \\ Microbiology ${ }^{1}$ and \\ Department of Oral \\ Biology2, University of \\ Aarhus, the Bartholin \\ Building, DK-8000 Aarhus \\ C, Denmark \\ 3,4 Departments of \\ Pathology 3 and \\ Biochemistry4, University \\ of Pennsylvania, School \\ of Dental Medicine, \\ 4010 Locust Street, \\ Philadelphia, 19104-6002, \\ USA
}

\begin{abstract}
The Actinobacillus actinomycetemcomitans population consists of a large number of clones among which the ubiquitous leukotoxin gene operon appears very homogeneous. Population genetic analyses performed by multilocus enzyme electrophoresis together with DNA fingerprinting and analyses of genomic DNA restriction fragment length polymorphisms (RFLP) on 97 strains isolated over a period of 45 years revealed that each of the serotypes a, b, c, d and e comprise genetically isolated subpopulations and that successful horizontal transfer of genomic DNA between strains of different serotypes appears to be extremely rare in vivo. In contrast, recombination between strains of the same serotype in general appears to take place in nature. The results provide evidence that non-serotypeable strains are serotype antigen-deficient variants originating from strains of the known serotypes. Serotype $b$ and c strains may contain transmittable DNA sequences not found in strains of the other serotypes.
\end{abstract}

Keywords: Actinobacillus actinomycetemcomitans, population genetic analysis, multilocus enzyme electrophoresis, leukotoxin gene operon, restriction fragment length polymorphism

\section{INTRODUCTION}

The Gram-negative capnophilic rod Actinobacillus actinomycetemcomitans has been implicated in the aetiology of progressive and localized juvenile periodontitis (Slots $e t$ al., 1980; Zambon et al., 1983a). The species may be detected also in periodontally healthy subjects and in healthy sites in patients with localized juvenile periodontitis. It is not known if these commensals and those associated with disease have different virulence potential. A. actinomycetemcomitans possesses a variety of potential virulence factors including the ability to invade epithelial cells (Meyer et al., 1991), a potent endotoxin, and a membrane-bound leukotoxin which specifically kills human polymorphonuclear leukocytes and macrophages (Baehni et al., 1979). In contrast to healthy individuals, most patients with juvenile periodontitis have serum antibodies that neutralize the leukotoxin (Baehni et al., 1981 ; McArthur et al., 1981).

The molecular biology of the A. actinomycetemcomitans

Abbreviations: ET, multilocus electrophoretic type; MEE, multilocus enzyme electrophoresis; RFLP, restriction fragment length polymorphism. leukotoxin has been extensively studied (Kolodrubetz et al., 1989; Lally et al., 1989a, b, 1991; Guthmiller et al., 1990a, b; Kraig et al., 1990). It is a member of the RTX (repeat in toxin) family of bacterial toxins which include the Pasteurella baemolytica leukotoxin, the cyclolysin of Bordetella pertussis, and certain Escherichia coli and Actinobacillus pleuropneumoniae haemolysins. This family of cytolysins are encoded by similarly organized gene operons, termed lk.t or ltx in A. actinomycetemcomitans, with the structural gene flanked by three other genes required for activation and transport of the toxin. Thus, in $A$. actinomycetemcomitans the leukotoxin gene, ltx $A$, is preceded by the $l t \times C$ gene which encodes a protein essential for activation of the leukotoxin. Downstream of It $x A$ are two other genes, lt $\times B$ and $\operatorname{lt} \times D$, that encode factors involved in transport of the toxin to the cell surface. There is limited information on the genetic polymorphism of the leukotoxin gene operon in the $A$. actinomycetemcomitans population (Guthmiller et al., 1993).

Five serotypes, termed a to e, of $A$. actinomycetemcomitans have been identified (Zambon et al., 1983b; Saarela et al., 1992). The serotype antigenic determinants presumably reside in the carbohydrate moiety of cell-wall lipopoly- 
saccharide (Page et al., 1991; Wilson \& Schifferle, 1991; Gmür et al., 1993). Serotype b is more prevalent in periodontally diseased patients compared to healthy subjects in whom serotype c predominates (Zambon $e$ t al., 1983b; Asikainen et al., 1991). Differences in virulence potential of the serotypes may thus occur, but the molecular nature of such disease-associations has not been investigated.

Population genetic studies based on multilocus enzyme electrophoresis (MEE) have revealed that certain clones or subpopulations of bacterial species may be more virulent than others due either to a particularly virulent allele of a single locus or to a particularly pathogenic combination of genes encoding distinct virulenceassociated factors (Musser $e t$ al., 1985, 1991; Caugant et al., 1987; Selander et al., 1990; Helmig et al., 1993). The genetic structure of bacterial populations may reflect pathogenicity of the species. Thus, among pathogenic bacteria most of the disease is caused by a single or very few clones that are rapidly disseminated in the susceptible host population (Musser et al., 1985, 1991; Caugant et al., 1987; Selander et al., 1990) whereas opportunistic pathogens tend to be genetically more diverse (Musser et al., 1986; Loos et al., 1993). Data from MEE can reveal the extent of recombination in bacterial species and, in the absence of extensive recombination, may provide valuable fundamental information for epidemiological studies and a framework for studies of virulence-associated phenotypic traits.

The present study was undertaken to construct a phylogenetic framework to evaluate the genetic relationships among $A$. actinomycetemcomitans strains and to disclose possible associations of serotype with genetic polymorphisms within the leukotoxin gene operon.

\section{METHODS}

Bacterial strains. A collection of 97 isolates of A. actinumycetemcomitans was examined (see Fig. 1). The collection included strains obtained from The National Collection of Type Cultures (NCTC), Colindale, London including the type strain NCTC 9710; The American Type Culture Collection (ATCC), Rockville, MD; Dr Wilhelm Frederiksen, Statens Seruminstitut, Copenhagen, Denmark (strains isolated by Dr Per Holm between 1946 and 1964 and designated PH); Dr T. J. M. van Steenbergen, ACTA, Amsterdam, The Netherlands (strains designated HG); Dr Jan Carlsson, Department of Oral Micro. biology, University of Umeå, Sweden (strains designated JC); Dr Ingegerd Kallings, Statens Bakteriologiska Laboratorium. Stockholm, Sweden (strains designated IK); Dr W. Mannheim, Department of Medical Microbiology, University of Marburg, FRG (strains designated HIM); Dr B. Guggenheim, Department of General Immunology and Oral Microbiology, University of Zürich, Switzerland (strains designated OMZ); and Dr Sirkka Asikainen, Department of Oral Microbiology, University of Helsinki, Finland (strains designated SA). The remaining strains designated $\mathrm{HK}$ were our own isolates. The majority (55) of the strains had been isolated from subgingival dental plaque including plaque from patients with periodontal diseases, eight strains were from cases of endocarditis or septicaemia, 24 were from abscesses including actinomycotic processes, and 10 strains were from other clinical conditions or were of unknown origin. The strains spanned 45 years in isolation time.

Serotyping of strains. Serotyping was performed by double immunodiffusion in a $1 \%(\mathrm{w} / \mathrm{v})$ agarose gel using autoclaved extracts of bacteria harvested from a broth culture and washed in PBS. Antisera against serotypes a, b and $\mathrm{c}$ were developed in rabbits by intravenous immunization using three reference strains: ATCC 29523 (serotype a), OMZ 295 (serotype b), and NCTC 9710 (serotype c). Antisera against serotypes d and e were kindly provided by Dr Sirkka Asikainen (Asikainen $e t$ al., 1991).

Enzyme electrophoretic typing. Bacterial lysates were prepared by sonication, electrophoresed in starch gels, and selectively stained for activity of each of 14 metabolic enzymes as described previously by Selander $e$ t al. (1986). The enzymes assayed were: nucleoside phosphorylase (NSP), peptidase (PEP), malic enzyme (ME), adenylate kinase (ADK), 6-phosphogluconate dehydrogenase (6PG), malate dehydrogenase (MDH), phosphoglucose isomerase (PGI), carbamate kinase (CDK), leucine aminopeptidase (LAP), alkaline phosphatase (ALK), glyceraldehyde-3-phosphate dehydrogenase (G3P), phosphoglucomutase (PGM), glucose-6-phosphate dehydrogenase (G6P), and mannose phosphate isomerase (MPI). Absence of enzyme activity was treated as missing data.

Genetic diversity at an enzyme locus $(b)$ among strains, i.e. the probability that two randomly chosen strains have different alleles of the locus, was calculated from allele frequencies as $b=1-\sum x_{i}^{2}[n /(n-1)]$, where $x_{i}$ is the frequency of the $i$ th allele of the locus and $n$ is the number of strains. Each combination of electrophoretic mobility of the 14 enzymes defined an ET (multilocus electrophoretic type). Genetic distance between ETs was expressed as the proportion of enzymes at which dissimilar electrophoretic mobility occurred. The dendrogram was constructed from computerized cluster analysis performed by the average-linkage method from a matrix of pairwise genetic distances between ETs using a program kindly provided by $\mathrm{Dr}$ T. S. Whittam, Department of Biology, Institute of Molecular Evolutionary Genetics, Pennsylvania State University, University Park, PA, USA.

Restriction endonuclease fingerprinting. Total cellular DNA of $A$. actinomycetemcomitans was extracted by the method previously described (Poulsen et al., 1988) except that RNase treatment was omitted. The quality and concentration of DNA was assayed by gel electrophoresis. Fingerprints were performed using DNA digested with the restriction enzymes HaeIII and XbaI. Approximately $2 \mu \mathrm{g}$ whole-cell DNA was digested with 10 units of HaeIII. The fragments were separated by electrophoresis in $0.9 \%$ agarose gels for $16 \mathrm{~h}$ at $2 \mathrm{~V} \mathrm{~cm}^{-1}$ in TAE buffer (0.04 M Tris/acetate, $0.002 \mathrm{M}$ EDTA) and visualized by staining with ethidium bromide (Sambrook et al., 1989). Strains for which the HaeIII fingerprint looked alike were subsequently run in parallel on the same gel to facilitate visual comparison. For the XbaI fingerprinting about $5 \mu \mathrm{g}$ DNA was restricted and applied to the gel. All enzymes were from Boehringer Mannheim.

Ribotyping and RFLP analysis. Total cellular DNA ( $2 \mu \mathrm{g})$ was digested with EcoRI and electrophoresed as described above. The nucleic acids were blotted and fixed onto Nytran nylon membranes (Schleicher \& Schuell) and the hybridizations were carried out as described (Sambrook et al., 1989) except that the filters were soaked in $1 \%(\mathrm{v} / \mathrm{v})$ Triton X-100 prior to prehybridization and $0 \cdot 1 \%$ sodium py rophosphate was included in all solutions. The final posthybridization wash was at $65^{\circ} \mathrm{C}$ in $1 \times \operatorname{SET}(0.15 \mathrm{M} \mathrm{NaCl}, 0.5 \mathrm{mM}$ EDTA, $20 \mathrm{mM}$ Tris $/ \mathrm{HCl}$, 
pH 7.0) containing $0 \cdot 1 \%$ SDS and $0 \cdot 1 \%$ sodium pyrophosphate. The same filters were used for hybridization with each of the probes and the filters were stripped between hybridizations by immersing in 1 litre boiling $0.1 \%$ SDS and left to cool for $30 \mathrm{~min}$. The probe for ribotyping was prepared by randomlyprimed reverse transcription of $16 \mathrm{~S}$ and $23 \mathrm{~S}$ ribosomal RNA from E. coli (Boehringer Mannheim) using MuLV reverse transcriptase (Boehringer Mannheim) and including $\left[{ }^{32} \mathrm{P}\right] \mathrm{d}$ ATP (Amersham) in the reaction as described by Sambrook et al. (1989). The probes used for RFLP analyses of the ltx operon were fragments of genomic DNA amplified by PCR and purified by Promega Magic PCR Preps (Promega). The fragments were: delta530 (this paper); ltxC, nt 127-635 (Lally et al., 1989a); It $\times A$, nt 635-3736 (Lally et al., 1989a); ltxB, nt 89-2121 (Lally et al., 1991); and ltxD, nt 2139-3570 (Lally et al., 1991). The anonymous genomic probes were restriction fragments of recombinant $\lambda$ phages originating from a library of genomic DNA prepared from $A$. actinomycetemcomitans strain JP2 cloned into $\lambda$ DASH II (E. T. Lally, unpublished). Phage DNA restricted with the appropriate enzymes was electrophoresed in agarose gels and the fragments of interest were purified by the Geneclean procedure (Bio 101). In addition, we used as probes the DNA insert of two recombinant plasmids, pSC2 and pSC3, originating from a plasmid library of DNA from strain JP2 which have previously been shown not to hybridize to a number of other $A$. actinomycetemcomitans strains (E. T. Lally, unpublished). All DNA fragments used as probes in the hybridizations were labelled with $\left[{ }^{32} \mathrm{P}\right] \mathrm{dATP}$ by nick translation (Sambrook et al., 1989).

\section{RESULTS}

The 97 A. actinomycetemcomitans strains analysed had been isolated over the last 45 years from healthy carriers as well as from infections. To characterize the genotype of each isolate we used different methods including serotyping, multilocus enzyme electrophoretic genotyping, DNA fingerprinting, ribotyping, and RFLP analyses using as probes the leukotoxin gene operon as well as anonymous DNA fragments originating from the $A$. actinomycetemcomitans genome and from DNA found only in strain JP2.

\section{Serotyping}

Of the 97 strains analysed 29,28, 27, 2 and 3 could be assigned to the known serotypes a, b, c, d and e, respectively. Autoclave extracts of the remaining eight strains did not react with any of the five antisera (Fig. 1). These non-serotypeable strains included OMZ300 which presumably originates from strain ATCC 29523. This reference strain was used for raising serotype a antibodies indicating that serotype is a phenotypic trait which can be lost during subcultivation.

\section{Genetic diversity and relationships revealed by enzyme electrophoretic typing}

Each of the $97 \mathrm{~A}$. actinomycetemcomitans strains were characterized by determining the electrophoretic mobility of 14 intracellular metabolic enzymes. These data are available upon request. Eleven of the enzymes were polymorphic with two to six alleles per locus (Table 1). Mean genetic diversity per locus was $0 \cdot 34$. Among the 97 strains we identified 50 ETs (multilocus electrophoretic types) each characterized by a distinct combination of electrophoretic mobility of the 14 enzymes. Thirty of the ETs were represented by a single strain whereas the remaining 20 ETs contained from 2 to 11 isolates (Fig. 1). Eight of these 20 ETs contained strains of different serotypes including non-typeable strains.

The genetic distance between ETs calculated as the proportion of the 14 enzyme loci at which dissimilar alleles are present was used to construct the dendrogram shown in Fig. 1. The smallest genetic distance between ETs was 0.07 corresponding to a single difference among the 14 enzymes analysed. Based on the structure of the phylogenetic tree we defined six ET divisions termed I to VI separating at average genetic distances between 0.34 and 0.49 (Fig. 1). The ET divisions II, IV and VI were represented by a single ET containing one or two strains and $\mathrm{ET}$ division $\mathrm{V}$ contained three ETs each represented by a single strain. The two major ET divisions, I and III, constituted $34 \%$ and $58 \%$ of the strains analysed, respectively. The average genetic distance between ETs of these two ET divisions was 0.49 . The mean genetic diversity per locus among the 33 strains in ET division I was $0 \cdot 12$ and the comparable value among the 57 strains in ET division III was $0 \cdot 19$. In ET division I, 7 of the 14 enzymes were monomorphic whereas ET division III had five invariable loci. These two major ET divisions of the $A$. actinomycetemcomitans population appear to be genetically distinct. Thus, alleles of the ADK, MDH and PGI loci were not shared in the two divisions.

Strikingly, we observed a strong correlation between serotype of the isolates and their ET affiliation. Thus, strains of serotype a were exclusively found in ET divisions $I$ and V whereas ET division III contained all the strains of serotypes $b$ and $c$ analysed except for the single serotype c strain which constituted ET division IV. The two serotype d strains belonged to a separate cluster in ET division $I$ and the three serotype $e$ strains constituted ET divisions II and VI. The eight nontypeable strains were found scattered throughout the ET divisions I, III and V.

\section{Genetic diversity and relationships revealed by restriction endonuclease typing}

To further examine the genomic clonality among strains assigned to the same E'T and to estimate the genetic similarity between strains at the DNA level we analysed the restriction endonuclease cleavage pattern of whole cell DNA for 86 of the 97 strains. DNA fingerprinting was based primarily on the restriction enzyme HaeIII. In addition, we performed EcoRI fingerprinting on each strain for subsequent Southern blotting but, as noted by Han et al. (1991), the distribution of bands created by this enzyme is too complex for easy visual analysis. As shown in Fig. 2 the banding profile created by HaeIII in the top part of the gel contains a few separate bands each presumably representing single DNA fragments in the size range $>10 \mathrm{~kb}$. This makes it feasible to compare visually the patterns created by this enzyme. The sen- 


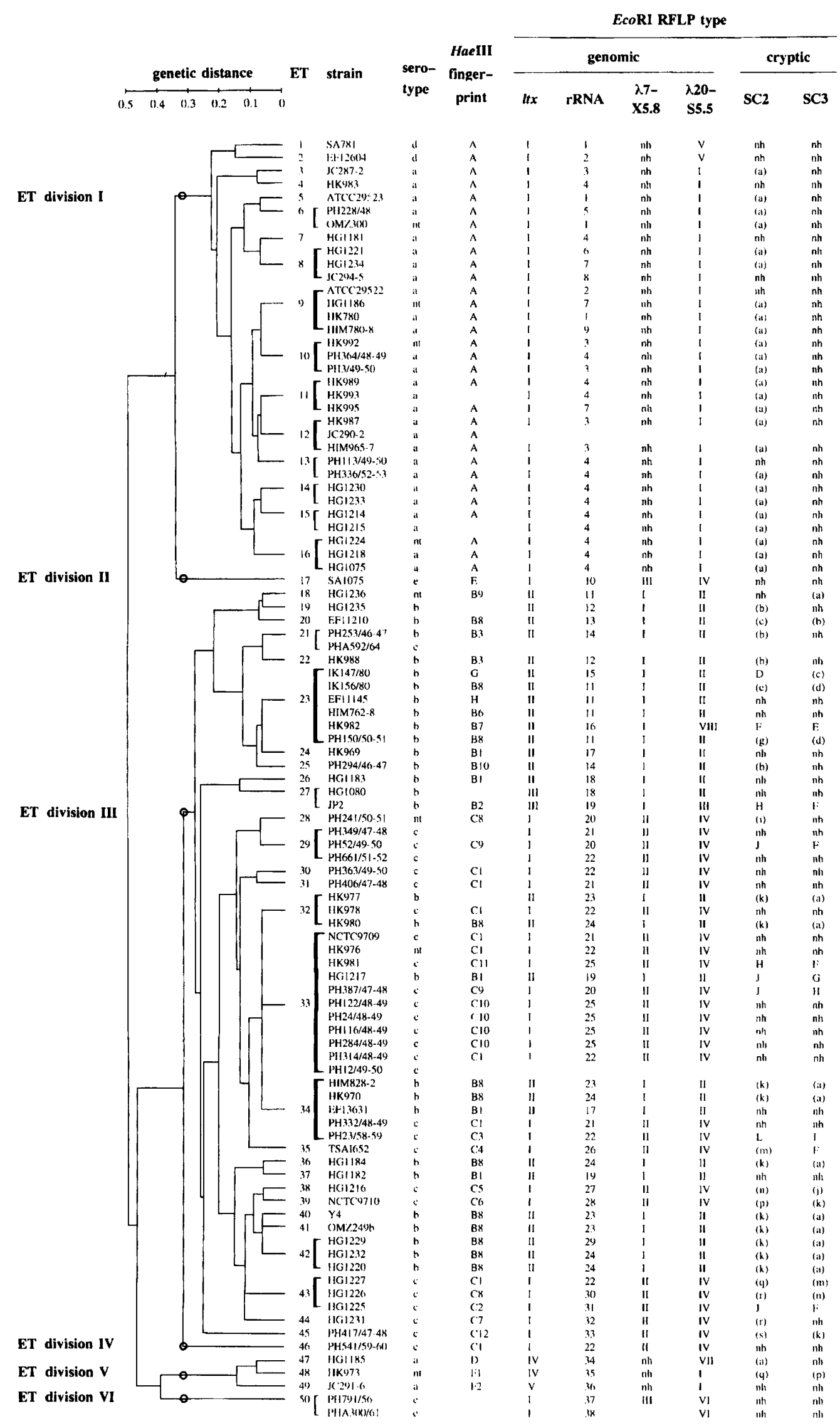

Fig. 1. For legend see facing page. 
Table 1. Number of electrophoretic alleles and genetic diversity per enzyme locus for 97 isolates of $A$. actinomycetemcomitans

\begin{tabular}{|lcc|}
\hline $\begin{array}{l}\text { Enzyme } \\
\text { locus* }\end{array}$ & $\begin{array}{c}\text { No. of } \\
\text { alleles }\end{array}$ & $\begin{array}{c}\text { Genetic } \\
\text { diversity }\end{array}$ \\
\hline NSP & 1 & 0 \\
PEP & 1 & 0 \\
ME & 1 & 0 \\
ADK & 2 & $0 \cdot 47$ \\
GPG & 4 & $0 \cdot 52$ \\
MDH & 4 & $0 \cdot 49$ \\
PGI & 3 & $0 \cdot 64$ \\
CDK & 2 & $0 \cdot 11$ \\
LAP & 3 & $0 \cdot 13$ \\
ALK & 3 & $0 \cdot 52$ \\
G3P & 5 & $0 \cdot 68$ \\
PGM & 4 & $0 \cdot 18$ \\
G6P & 5 & $0 \cdot 37$ \\
MPI & 6 & $0 \cdot 61$ \\
Mean & $3 \cdot 1$ & $0 \cdot 34$ \\
\hline
\end{tabular}

* Abbreviations as in Methods.

sitivity of the staining procedure together with the amount of HaeIII-digested DNA applied to the gel imply that each of the visible bands in the lower part of the gel represents several DNA fragments migrating together. Therefore, this part of the fingerprint merely reflects the overall location of $\mathrm{HaeIII}$ sites in the genome and thereby provides a means to estimate the genetic similarity of strains. Based on such similarities, the HaeIII fingerprints of the 86 strains were divided into eight classes termed A to $\mathrm{H}$ whereas minor differences within each class were indicated by a number. The results are shown in Fig. 1. Since differences in fingerprints may be influenced by the possible presence of plasmid DNA in the whole-cell DNA preparations we examined 72 of the strains by agarose gel electrophoresis of approximately $2 \mu \mathrm{g}$ whole-cell DNA treated with RNase. This screening method may overlook the presence of plasmids in some strains since the DNA purification protocol does not enrich for plasmid DNA, yet the method reveals whether the whole-cell DNA preparations contain extrachromosomal DNA in amounts that may influence the HaeIII fingerprints. DNA from only two strains, IK147/80 and EF11145 both of serotype $\mathrm{b}$ and ET type 23, were found to contain visible DNA bands migrating differently from the chromosomal DNA. The two apparent plasmids migrated at different rates.
The two strains containing extrachromosomal DNA each had a unique HaeIII fingerprint which might be influenced by the plasmid content. We cannot exclude that whole-cell DNA from some of the remaining strains may contain DNA from very large plasmids which migrates at the same rate as chromosomal DNA.

Genetic separation of the $97 \mathrm{~A}$. actinomycetemcomitans strains into ET divisions based on MEE typing as revealed by the dendrogram (Fig. 1) was confirmed by the restriction enzyme analyses. Thus, no class of HaeIII fingerprint was shared among the ET divisions except for the single serotype c strain in ET division IV, which was similar to serotype c strains found in ET division III. In addition, these analyses revealed that the degree of genetic variation is different in the two major ET divisions. Strains in ET division I were very homogeneous in that their HaeIII fingerprints all looked alike. This confirms the close evolutionary relationships between the serotype $\mathrm{d}$ strains and this major part of the serotype a population. In contrast, we found heterogeneity among strains assigned to ET division III. Notably, the HaeIII fingerprint analyses divided most strains of this ET division into two classes, B and $\mathrm{C}$, each containing exclusively serotype $\mathrm{b}$ and serotype $\mathrm{c}$ strains, respectively. This result indicates the existence of overall and specific genetic similarities within each of the two serotypes not revealed by the MEE method.

All eight non-typeable strains had HaeIII fingerprints closely resembling those of strains of known serotypes within the same division.

To test for clonality among strains assigned to the same ET in ET division I, which was extremely homogeneous, we compared the DNA fingerprints generated by the restriction enzyme XbaI. This enzyme has previously been found useful in differentiating individual strains of A. actinomycetemcomitans (Han et al., 1991). Since digestion of the $A$. actinomycetemcomitans genome with this enzyme produces a limited number of fragments $<10 \mathrm{~kb}$ in size it is possible to compare the position of single fragment bands in the region $2-10 \mathrm{~kb}$. To visualize these small fragments by staining with ethidium bromide, approximately $5 \mu \mathrm{g}$ DNA from each strain was digested and applied to the gel because the estimated amount of DNA in the band of a $2 \mathrm{~kb}$ fragment of the genome would then be about $4 \mathrm{ng}$ which is close to the lower limit for detection. The large amount of DNA applied to the slots resulted in problems with overloading the gel, and the quality of the $X b a \mathrm{I}$ fingerprints did not allow us to compare all the serotype a strains, yet the method clearly demonstrated heterogeneity within ET6, ET9, ET10,

Fig. 1. Genetic relationships among the 97 strains of $A$. actinomycetemcomitans analysed. The dendrogram was constructed from the ET typing data. ETs are numbered sequentially from top to bottom. Six major lineages (ET divisions) separating at a genetic distance of 0.34 are indicated to the left by circles in the dendrogram. The columns to the right indicate results for serotype, Haelll fingerprinting, EcoRI RFLP types using as probes the leukotoxin gene operon (/tx), ribosomal RNA (rRNA), two anonymous genomic DNA fragments ( $\lambda 7-\times 5.8$ and $\lambda 20-\$ 5.5$ ) and two fragments originally found specific for strain JP2 (SC2 and SC3). See text for nomenclature of the individual typings. Abbreviations: nt, nontypeable; nh, no hybridization. Lower-case letters in parentheses indicate weak hybridizations. 


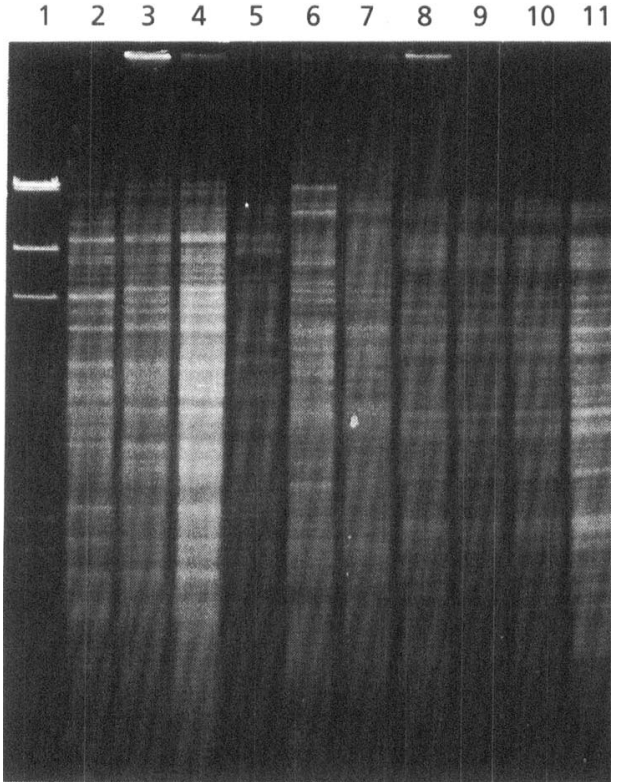

Fig. 2. Haelll restriction endonuclease fingerprinting of $A$. actinomycetemcomitans. Lane 1, molecular mass marker (23, $9.4,6.6,4.4,2.3$ and 2.0 kb); lane 2, PH387/47-48 (serotype c); lane 3, HK976 (non-typeable); lane 4, NCTC9709 (serotype c); lane 5, PH150/50-51 (serotype b); lane 6, JC291-6 (serotype a); lane 7, HG1185 (serotype a); lane 8, JC287-2 (serotype a); lane 9. ATCC29523 (serotype a); lane 10, HG1224 (non-typeable); lane 11, HK992 (non-typeable).

ET11 and ET12. On this basis we conclude that the restriction enzyme analyses support and supplement the: results obtained from the $\mathrm{MEE}$ analyses and show that the $A$. actinomycetemcomitans population is composed of a very large number of clones.

\section{Genetic diversity of the leukotoxin gene operon}

To test whether the overall genetic relationships observed also applied to a putative virulence factor, like the leukotoxin, we used RFLP analyses to assay for variation of the ltx operon region in the population of $A$. actinomycetemcomitans. Southern blots of EcoRI-restricted whole-cell DNA from 94 of the 97 strains in the collection were hybridized with DNA probes specific for each of the four genes in the ltx operon. We observed a very limited degree of genetic variation. Figs 3 and 4 show the five EcoRI fragment length types of the ltx operon region identified, termed $\mathrm{I}$ to $\mathrm{V}$, and the type of each strain is shown in Fig. 1. Among strains that exhibited the type II Itx operon we observed a slight variation in size of the $8.2 \mathrm{~kb}$ EcoRI fragment which hybridized with the lt $x A$ and $l t \times D$ probes (Fig. 3, lanes 3 and 4), but the differences were too small to be consistently scored. Some faint bands (e.g. Fig. 3, lane 5) were found to originate from nonspecific 'star' activity of the EcoRI enzyme.

The EcoRI RFLP type of the ltx operon region correlated strongly with serotype of the strains. Thus, all serotype a and $\mathrm{d}$ strains in ET division I, the three serotype e strains which constitute ET divisions II and VI, and all serotype c strains exhibited identical hybridization pattern. In contrast, the three strains in ET division $\mathrm{V}$ including two of serotype a have leukotoxin gene types different from the other strains. All serotype b strains except two had the same unique hybridization pattern. The two exceptions, JP2 and HG1080, had an identical EcoRI RFLP type of the lt $x$ operon. In another study we have shown that these two strains are characterized by a 530 bp deletion in the ltx promoter region and that they both have highly elevated production of leukotoxic activity compared to strains representing the two major ltx operon types (Brogan et al., 1994). To determine whether the deletion is unique to these two strains in the collection of $A$. actinomycetemcomitans the Southern blots of EcoRI-restricted whole-cell DNA were hybridized with the 530 bp DNA fragment termed delta530 present in $A$. actinomycetemcomitans strain 652 , which presumably originates from the same isolate as TSAI652 in our collection. All the other strains tested hybridized to delta530.

The eight non-typeable strains all had EcoRI RFLP types of the ltx operon identical to closely related strains of known serotypes.

\section{Ribotyping and genetic diversity revealed by genomic RFLP typing}

The conclusions on the genetic structure of the $A$. actinomycetemcomitans population based on each of the three typing methods described so far, MEE typing, DNA fingerprinting and RFLP analyses of the ltx operon, differed slightly. To clarify this we performed EcoRI RFLP analyses using an additional three probes for hybridization. One of the probes was specific for the ribosomal RNA genes whereas the other two were anonymous genomic DNA fragments originating from A. actinomycetemcomitans strain JP2 and for which the coding potential is unknown.

Ribotyping using reverse-transcribed $16 \mathrm{~S}$ and $23 \mathrm{~S}$ rRNA from E. coli as probe for hybridization with the Southern blots of EcoRI-restricted whole-cell DNA from each of the 94 isolates analysed revealed five to nine bands in the size range $3-20 \mathrm{~kb}$ (Fig. 3). Notably, all strains except HG1216 (not shown) exhibited a characteristic pattern of the three weakly hybridizing lower bands of $3.0 \mathrm{~kb}, 3 \cdot 2 \mathrm{~kb}$ and $3.6 \mathrm{~kb}$, respectively (Fig. 3). Strain HG1216 lacked the band at $3.0 \mathrm{~kb}$ (not shown). The number and size of the other larger and strongly hybridizing EcoRI fragments varied, and among the 94 strains analysed we identified a total of 38 distinct ribotypes, designated 1 to 38 , of which 16 were represented by more than one strain (Fig. 1). We observed a correlation between ribotype and ET division as well as serotype. No two strains of the same ribotype were found in different ET divisions except for the single serotype $\mathrm{c}$ strain in ET division IV which had the same ribotype as serotype $\mathrm{c}$ strains in ET division III. All strains of identical ribotype were of the same serotype or were non-typeable. In contrast, there was no strong correlation either between HaeIII fingerprinting type and ribotype or between ET type within E'T divisions and 


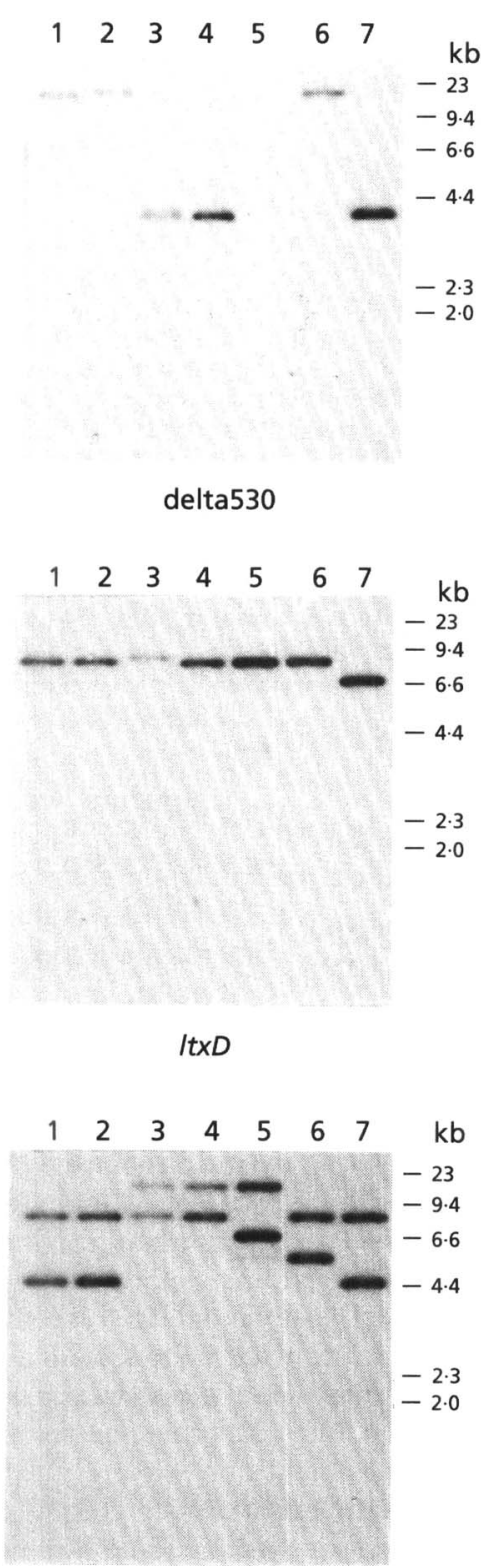

$\lambda 20-\$ 5.5$

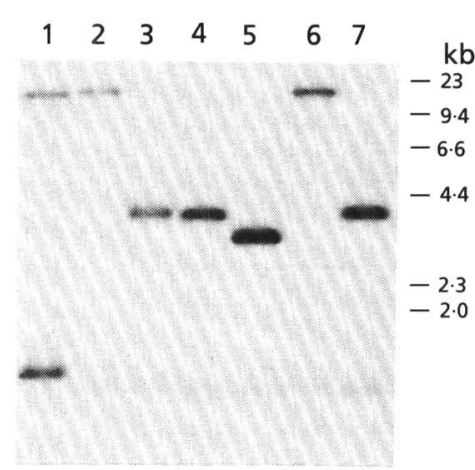

ItxC

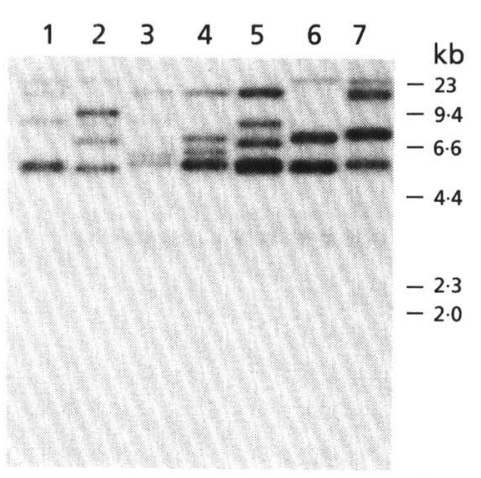

rRNA

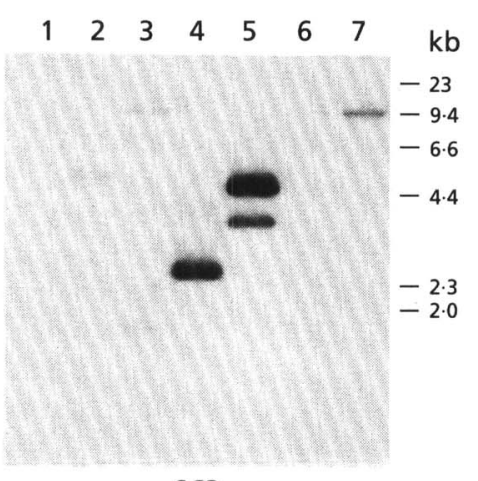

SC2

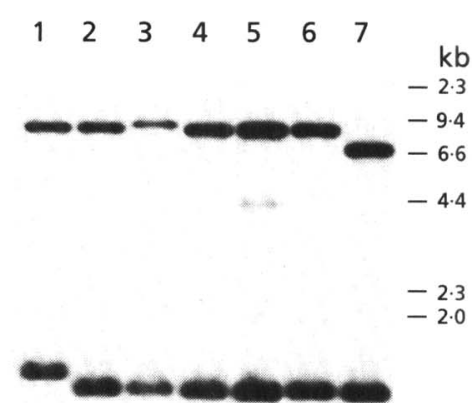

ItxA

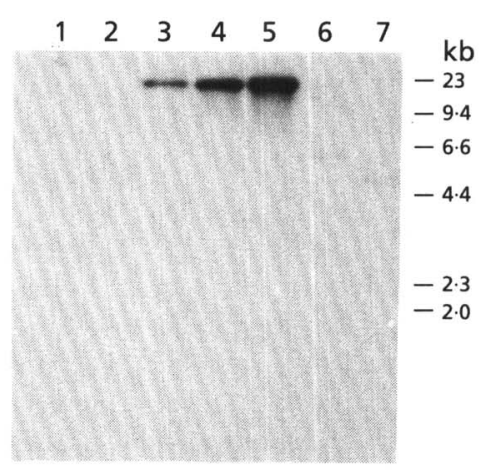

$\lambda 7-\times 5.8$

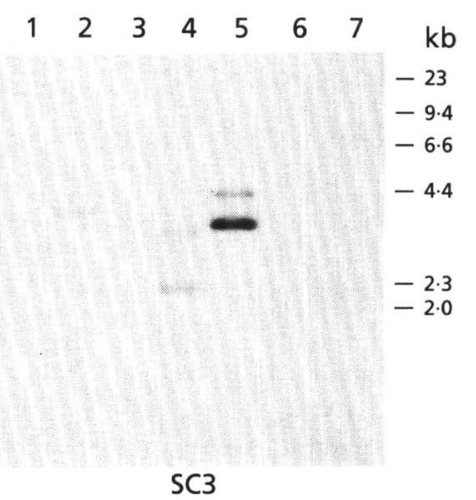

Fig. 3. ECORI RFLP typing of whole-cell DNA from A. actinomycetemcomitans. The figure shows the autoradiograms of a Southern blot of EcoRI-restricted DNA from strains JC291-6 (lane 1), HK973 (lane 2), HG1232 (lane 3), IK147/80 (lane 4), JP2 (lane 5), HG1185 (lane 6) and HK995 (lane 7) hybridized sequentially with each of the nine probes delta530, ItxC, ItxA, and $I$ txD from the leukotoxin gene operon; ribosomal RNA (rRNA); the anonmyous genomic DNA fragments $\lambda 7-\times 5.8$ and 220-S5.5; and the fragments SC2 and SC3 representing sequences specifically found in strain JP2 as described in the text. Molecular mass markers are indicated to the right of each autoradiogram.

ribotype. Thus, we found several examples of strains with identical HaeIII fingerprint but with different ribotype and vice versa. Similar relationships applied to ET type compared to ribotype. These observations suggest that recombination between strains of the same ET division and serotype may occur in vivo.

The recombinant phages $\lambda A a \mathrm{JP} 2-7$ and $\lambda A a \mathrm{JP} 2-20$ were randomly chosen from a genomic library of $A$. actinomycetemcomitans strain JP2. As anonymous probes for
EcoRI RFLP analyses we used a $5.8 \mathrm{~kb} \mathrm{XbaI} \mathrm{fragment} \mathrm{of}$ $\lambda A a \mathrm{JP} 2-7$ termed $\lambda 7-\mathrm{X} 5.8$ and a $5.5 \mathrm{~kb}$ Sall fragment of $\lambda A a \mathrm{JP} 2-20$ termed $\lambda 20$-S5.5. Due to the cloning procedure these fragments might, in addition to genomic DNA from strain JP2, contain a small part of the polylinker region from the phage vector Lambda DASH II.

The $\lambda 7-X 5.8$ fragment hybridized strongly to one or two EcoRI fragments of whole-cell DNA from 58 of the 93 
(a)

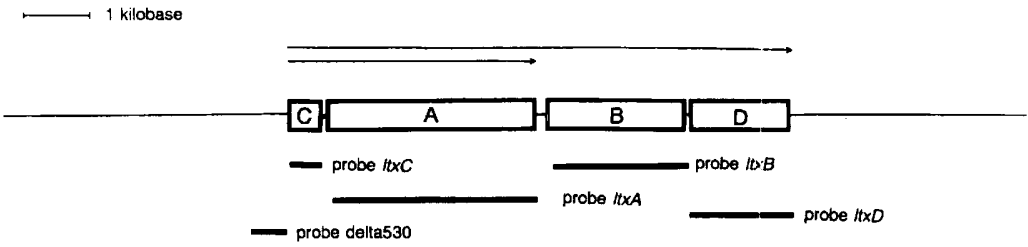

(b)

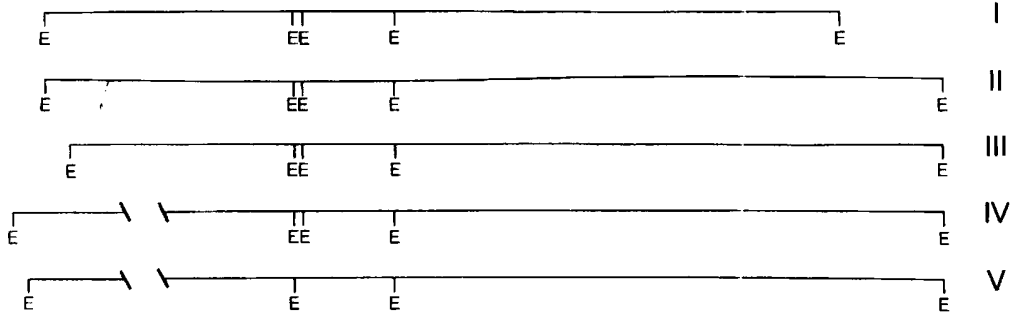

Fig. 4. Physical map of the leukotoxin gene operon. (a) Location of the genes ItxC (C), ItxA (A), ItxB (B), and ItxD (D) in the leukotoxin gene operon from $A$. actinomycetemcomitans strain 652. Arrows indicate the transcripts from the operon. Notably, additional transcripts are found in strain JP2 (Brogan et al., 1994). Bars below show the location of the five hybridization probes used for EcoRI RFLP mapping of the leukotoxin operon. (b) The five EcoRI RFLP types, termed I to $V$, of the leukotoxin operon detected among the 94 strains analysed. E, EcoRI sites. strains analysed, whereas DNA from the remaining 35 strains showed only very weak hybridization with this probe (Fig. 3). Among the hybridizing strains we found only three different EcoRI RFLP types termed I, II and III. These types correlated completely with the serotype of the strains. Thus, none of the 28 serotype a or two serotype d strains hybridized strongly with $\lambda 7-\mathrm{X} 5.8$, all 28 strains of serotype $\mathrm{b}$ were of type I hybridization pattern. all 25 serotype $\mathrm{c}$ were of type II, and both serotype e strains analysed exhibited the same type III EcoRI RFLP pattern with this probe (Fig. 1).

The $\lambda 20$-S5.5 fragment hybridized strongly to DNA from all 94 strains tested (Fig. 3). The pattern of hybridizing EcoRI fragments revealed eight distinct RFLP types termed I to VIII. The EcoRI RFLP types detected by this probe also correlated very strongly with the serotype of the strains. Except for four strains, SA1075, HK982, JP2 and HG1185, each serotype was characterized by a unique EcoRI RFLP type using $220-\mathrm{S} 5.5$ as probe (Fig. 1). Notably, this probe distinguished the serotype $\mathrm{d}$ strains from those of serotype a. Strain SA1075 of serotype e had the same RFLP type as the serotype c strains whereas each of the other three exceptional strains had different RFLP types. Thus, these analyses show that, with a single exception, different alleles have been fixed in each of the serotypes of $A$. actinomycetemcomitans and thereby confirm that the serotypes constitute genetically isolated subpopulations.

The previous analyses suggested that the eight nontypeable strains had originated from one of the recognized serotypes. This was supported by the EcoRI RFLP typing revealed by these anonymous probes.

\section{Occurrence and diversity of the strain JP2-specific DNA sequences}

We have previously found that $A$. actinomycetemcomitans strain JP2 harbours DNA sequences not present in a number of other $A$. actinomycetemcomitans strains (E. T.
Lally, unpublished). Two EcoRI fragments with this property, SC2 of $4.5 \mathrm{~kb}$ and SC3 of $4.0 \mathrm{~kb}$, have been cloned into pUC19. We used the inserts of these recombinant plasmids as probes to test for hybridization with the Southern blots of EcoRI-restricted whole-cell DNA (Fig. 3).

Eight of the 94 strains analysed, HK982, JP2, PH52/4950, HK981, HG1217, PH387/47-48, PH23/58-59 and HG1225, showed strong hybridization with both SC2 and SC3. A single strain, IK147/80, hybridized with SC2 only and strain TSAI652 hybridized with SC3 but not SC2. Four of these 10 strains were of serotype $b$ and six were of serotype c. The hybridizing strains belonged to seven different ETs all found in ET division III. Five distinct patterns of strong hybridization with the EcoRI digests, each designated with an upper-case letter, were revealed by each of the two cryptic probes, and these patterns were found in six different combinations among the eight strains that hybridized with both probes (Fig. 1). The patterns of strong hybridization with SC2 and SC3 did not correlate with serotype of the strains. Notably, strain JP2 of serotype $b$ and strain HK981 of serotype $c$ had identical hybridization pattern using these two SC probes. Seven of the 10 strains that hybridized had unique HaelII fingerprints and two strains, PH52/49-50 and PH387/47-48, had an identical fingerprint not found among other strains in the collection. Remarkably, strain HG1217 had an HaeIII fingerprint identical to strains that did not hybridize strongly with the SC probes.

Among the 94 strains analysed the SC2 probe showed weak hybridization with 52 strains among which we identified 13 distinct EcoRI RFLP patterns each designated with a lower-case letter in parentheses in order to stress the weak hybridization (Fig. 1). Thirty-three strains did not hybridize with SC2 at all. Analogously, the SC3 probe revealed eight distinct EcoRI RFLP patterns among 21 weakly hybridizing strains whereas 64 strains did not hybridize with SC3. No two strains of different serotype exhibited an identical pattern of EcoRI fragments hybridizing weakly with SC2 or SC3 (Fig. 1). Several of the 
strongly hybridizing strains exhibited faint bands in addition to the strong ones. Together with the observed correlation between patterns of weak hybridizations and serotype, this suggests that the faint bands resulted from genomic sequences with a low degree of homology to the SC2 and SC3 fragments from the strain JP2-specific DNA sequences.

\section{DISCUSSION}

The population structure of bacterial species may show different degrees of clonality ranging from panmictic with random association of alleles to strictly clonal characterized by a few predominant combinations of alleles (Smith et al., 1993). The genetic structure depends on the extent of genetic recombination within the population as well as on the population biology of the species. Previous studies have provided conflicting results concerning the genetic diversity of the $A$. actinomycetemcomitans population. Thus, Caugant $e t$ al. (1990) found 11 different ET types among $17 \mathrm{~A}$. actinomycetemcomitans strains analysed, Saarela et al. (1993) showed that isolates from 20 different individuals were of different ribotypes, and Han et al. (1991) recognized 10 distinct genomic clonal types among 12 strains analysed by DNA fingerprinting using the restriction enzymes $S_{a} I \mathrm{I}, \mathrm{XboI}$ and $X b a I$. Using a panel of five DNA probes Guthmiller et al. (1993) also detected significant genetic variation among $35 \mathrm{~A}$. actinomycetemcomitans strains. In contrast, Zambon et al. (1990) reported a very limited genetic diversity of $A$. actinomycetemcomitans in that among 70 strains analysed they only recognized three different EcoRI and HindIII restriction fragment patterns. These three DNA fingerprints correlated with serotype of the strains whereas Guthmiller et al. (1993) found only partial association between DNA profile and serotype and DiRienzo \& Slots (1990) found no relatedness between serotype and EcoRI and HindIII RFLP types using an anonymous DNA probe. The general conclusion concerning the population biology of A. actinomycetemcomitans based on these studies is that individuals are colonized with a single or few clones and that infected members of the same family usually harbour the same strain. Furthermore, colonization with a particular clonal type may persist for several years.

In the present study of 97 isolates of $A$. actinomycetemcomitans MEE typing was combined with restriction enzyme analyses of the genome in general, the four ltx genes and the rRNA genes in particular, and with detection of DNA sequences specifically found in strain JP2. The strain collection spanned 45 years in time of isolation and originated from at least seven European countries and the USA. While MEE typing has been successfully applied to several bacterial species to reveal their overall phylogenetic structure, the DNA typing methods employed may reveal differences in the primary structure of the genome not necessarily related to gene expression.

A total of 50 ETs were detected among the 97 strains by the MEE analysis involving 14 metabolic enzymes (Fig.
1). The genetic distance between the ET types was similar to that reported by Caugant $e t$ al. (1990) based on MEE analysis of 17 strains. The dendrogram in Fig. 1 shows that the population clustered in six distinct subpopulations which correlated with serotype. The 29 serotype a strains belonged to two genetically very different divisions (ET divisions $\mathrm{I}$ and $\mathrm{V}$ ) of which the major one also included the two serotype $d$ strains which joined serotype a strains at a genetic distance of $0 \cdot 24$. Likewise, the three serotype e strains in the collection could be ascribed to two different divisions (ET divisions II and VI) (Fig. 1). Although more diverse, the 28 serotype b strains and 26 of the 27 serotype $\mathrm{c}$ strains analysed constituted ET division III but without demarcation between the two serotypes. The exceptional serotype c strain constituted ET division IV.

The other typing methods employed disclosed additional heterogeneity within the population as well as identities within and between serotypes. Thus, the HaeIII fingerprinting revealed that ET division I is very homogeneous compared to division III in which most ET types containing more than one strain were found to be heterogeneous. Using another restriction enzyme, XbaI, we demonstrated heterogeneity within some of the ET types in division I. Ribotype and RFLP type using genomic probes like the ltx gene and the anonymous genomic fragments $\lambda 7-X 5.8$ and $\lambda 20-S 5.5$ are chromosomal characteristics of the strains whereas DNA fingerprinting and RFLP type using the cryptic probes SC2 and SC3 may be influenced by the presence of plasmids in the strains. The rare presence of plasmids observed in our collection of $A$. actinomycetemcomitans strains is in agreement with results of LeBlanc et al. (1993) who found that among 39 laboratory strains examined only two harboured detectable plasmids. Possibly, some plasmids are lost during subcultivation since Olsvik \& Preus (1989) found that ten newly isolated strains all possessed plasmids. There was no correlation between hybridization with the two cryptic probes and presence of plasmid DNA. Together with ribotyping the genomic RFLP typing showed that among the $20 \mathrm{ET}$ types containing more than one strain only seven (ET13, ET14, ET15, ET16, ET23, ET33 and ET42) may contain genetically identical strains representing clones. We cannot exclude the possibility that some of these seemingly identical isolates may originate from the same or closely related subjects. The prevalence of single ETs may come about by random association of frequent alleles of the enzyme loci, hence strains that appear to have the same ET may not comprise a clone. Thus, the most predominant ET in this study, ET33, was characterized by a combination of the most frequent alleles for each of the enzymes in ET division III. Assuming random association of the alleles we would expect 5.5 strains with this ET compared to the 11 strains observed. Serotyping and analyses of the chromosomal DNA revealed that this ET contained strains of different genotypes as well as five serotype c strains which presumably represent a clone characterized by ribotype 25. Correspondingly, ET23 included four serotype $b$ strains which may represent a clone with 
ribotype 11. This proposed clonal structure of a part of ET23 was supported by the high number of strains with this ET compared to the expected number of 0.24 when assuming random association of alleles in ET division III. In contrast, the strains in another predominant ET, ET34, were all of different ribotype indicating that these strains do not comprise a clone. ET34 was represented by five strains which is of the same order of magnitude as the expected $2 \cdot 2$ strains if ET division III was in linkage equilibrium.

Combined, the different typing methods show that the $A$. actinomycetemcomitans population consists of a very large number of genotypes. Our data clearly demonstrate that the different typing methods supplement each other and that none of the methods alone was adequate in disclosing the genetic diversity among the strains. The high degree of polymorphism makes ribotyping particularly useful for epidemiological studies of $A$. actinomycetemcomitans.

While the MEE analyses indicated that the serotype $b$ and serotype $\mathrm{c}$ strains are evolutionarily closely related, the results obtained by the DNA typing methods are seemingly in conflict with this conclusion. Thus, the DNA fingerprints as well as the RFLP analyses of the genome suggest that strains assigned to each of the two serotypes are genetically distinct at the DNA level. Furthermore, the RFLP analyses of the ltx operon showed that at this region the majority of serotype a, c, d and e strains are similar and different from the serotype b strains. One possible explanation of these discrepancies could be that individual regions in the genome are subject to different frequencies of horizontal transfer between strains. Theoretically, differences in the overall organization of the genome of serotype b and c strains, possibly combined with inserts of DNA elements like phage and plasmid DNA, might be an alternative explanation. While such differences would affect the DNA typing patterns even if the gene loci are identical it would have no influence on the results of the MEE typing. Additional studies are necessary to explain these discrepancies in genetic relationships between the serotypes.

The observation that different alleles of three enzyme loci and different EcoRI RFLP patterns of chromosomal regions have been fixed in the subpopulations strongly indicates that recombination in nature between strains of the different phylogenetic divisions is very rare or absent. Conversely, within each of the three major clusters containing serotype $\mathrm{a}, \mathrm{b}$ and $\mathrm{c}$ strains we find no strong linkage between particular alleles of the variable characters such as individual polymorphic loci for metabolic enzymes, HaeIII fingerprint and ribotype indicating that recombination between strains of the same ET division and serotype takes place in vivo. The frequency of recombination is not high enough to result in linkage equilibrium as we detected few examples of apparently identical strains which may represent clones. Thus, our results suggest that the $A$. actinomycetemcomitans population consists of several genetically isolated subpopulations, to a large extent corresponding to the five serotypes, within which recombination occurs. The genetic distance between the individual subpopulations is similar to that observed between serovars of Salmonella (Selander et al., 1990).

Construction of a phylogenetic tree from MEE analyses as shown in Fig. 1 is based on evolutionary fixation in the population of selectively neutral mutations in the structural genes encoding the enzymes examined. It is important to stress that the finer structure of the tree within the major genetically isolated subpopulations is not necessarily valid as the postulated recombination events may blur the phylogenetic relationships of the strains (Biserčić et al., 1991).

The eight non-serotypeable isolates were distributed in widely different evolutionary lines of the population and were genetically very similar to other strains of the respective clusters. These findings indicate that our nonserotypeable strains of $A$. actinomycetemcomitans are serotype antigen-deficient variants of the known serotypes rather than belonging to a single as yet unrecognized serotype.

We used gene-specific hybridization probes for each of the four genes of the ltx operon to show that homologous sequences were present in all strains analysed and that the overall structure of the gene operon region, as revealed by the RFLP patterns, in general is conserved within the serotypes amounting to five RFLP patterns of the region (Fig. 1 and Fig. 4). These findings confirm the conclusions drawn by Spitznagel et al. (1991) that the previously observed lack of leukotoxic activity in some isolates mainly from healthy subjects is merely of quantitative nature and a result of different levels of transcription. In this context it is of particular interest that two strains, including JP2, both of serotype b and assigned to ET27, had the same unique version of the leukotoxin gene operon which correlated with highly elevated production of leukotoxic activity (Brogan et al., 1994). It is possible that ET27 represents a cluster of clonal types with increased virulence as previously postulated for strain JP2 by DiRienzo \& Slots (1990).

Several of the strains included in this study were isolated from cases of localized juvenile periodontitis or from systemic infections. However, we observed no apparent association between particular clusters of genotypes and disease (data not shown). One intriguing possibility is that pathogenicity is associated with the presence of transmittable DNA elements. Previous studies have shown that $A$. actinomycetemcomitans may harbour a variety of plasmids (Olsvik \& Preus, 1989; LeBlanc et al., 1993) and phages (Preus et al., 1987; Stevens et al., 1982). In the present study we found that whole-cell DNA from some strains of serotype b and c, but never serotype a, contained sequences homologous to the two probes SC2 and SC3 which originated from strain JP2. The lack of correlation between hybridization pattern using these two probes and the results from all the other genotyping methods suggests that SC2 and SC3 are contained within a transmittable DNA element. The nature and possible role in virulence of this hypothetical DNA element remains to be examined. 
With few potential exceptions this study revealed no evidence of single clonal types being responsible for multiple cases of infection. This is in striking contrast to what has been observed for recognized human pathogens like Haemophilus infuenzae serotype b (Musser et al., 1985), Streptococcus pyogenes (Musser et al., 1991), Neisseria meningitidis (Caugant et al., 1987) and Salmonella typhi (Selander et al., 1990) in which one or a few clones cause the vast majority of disease. In contrast, the observed population structure of $A$. actinomycetemcomitans with an almost indefinite number of clones is similar to that previously observed for opportunistic pathogens such as noncapsulated H. influenzae (Musser et al., 1986) and another suspected periodontal pathogen, Porphyromonas gingivalis (Loos et al., 1993).

\section{ACKNOWLEDGEMENTS}

This study was supported by the Danish Medical Research Council grant no. 12-1615, Colgate-Palmolive, Denmark, and by DE09517. We gratefully acknowledge Tine Poulsen for excellent technical assistance.

\section{REFERENCES}

Asikainen, S., Lai, C.-H., Alaluusua, S. \& Slots, J. (1991). Distribution of Actinobacillus actinomycetemcomitans serotypes in periodontal health and disease. Oral Microbiol Immunol 6, 115-118.

Baehni, P., Tsai, C.-C., McArthur, W. P., Hammond, B. F. \& Taichman, N. S. (1979). Interaction of inflammatory cells and oral microorganisms. VIII. Detection of leukotoxic activity of a plaquederived Gram-negative microorganism. Infect Immun 24, 233-243.

Baehni, P. C., Tsai, C.-C., McArthur, W. P., Hammond, B. F., Shenker, B. J. \& Taichman, N. S. (1981). Leukotoxic activity in different strains of the bacterium Actinobacillus actinomycetemcomitans isolated from juvenile periodontitis in man. Arch Oral Biol 26, 671-676.

Biserčić, M., Feutrier, J. Y. \& Reeves, P. R. (1991). Nucleotide sequences of the gnd genes from nine natural isolates of Escherichia coli: evidence of intragenic recombination as a contributing factor in the evolution of the polymorphic gnd locus. J Bacteriol 173, 3894- 3900.

Brogan, J. M., Lally, E. T., Poulsen, K., Kilian, M. \& Demuth, D. R. (1994). Regulation of Actinobacillus actinomycetemcomitans leukotoxin expression: analysis of the promoter regions of leukotoxic and minimally leukotoxic strains. Infect Immun 62, 501-508.

Caugant, D. A., Mocca, L. F., Frasch, C. E., Frøholm, L. O., Zollinger, W. D. \& Selander, R. K. (1987). Genetic structure of Neisseria meningitidis populations in relation to serogroup, serotype, and outer membrane protein pattern. J Bacteriol 169, 2781-2792.

Caugant, D. A., Selander, R. K. \& Olsen, I. (1990). Differentiation between Actinobacillus (Haemopbilus) actinomycetemcomitans, Haemophilus aphrophilus and Haemophilus paraphrophilus by multilocus enzyme electrophoresis. J Gen Microbiol 136, 2135-2141.

DiRienzo, J. M. \& Slots, J. (1990). Genetic approach to the study of epidemiology and pathogenesis of Actinobacillus actinomycetemcomitans in localized juvenile periodontitis. Arch Oral Biol 35, $79 \mathrm{~S}-84 \mathrm{~S}$.

Gmür, R., McNabb, H., van Steenbergen, T. J. M., Baehni, P., Mombelli, A., van Winkelhoff, A. J. \& Guggenheim, B. (1993). Seroclassification of hitherto nontypable Actinobacillus actinomycetemcomitans strains: evidence for a new serotype e. Oral Microbiol Immunol 8, 116-120.
Guthmiller, J. M., Kolodrubetz, D., Cagle, M.P. \& Kraig, E. (1990a). Sequence of the lkt $B$ gene from Actinobacillus actinomycetemcomitans. Nucleic Acids Research 18, 5291.

Guthmiller, J. M., Kraig, E., Cagle, M. P. \& Kolodrubetz, D. (1990b). Sequence of the lktD gene from Actinobacillus actinomycetemcomitans. Nucleic Acids Res 18, 5292.

Guthmiller, J. M., Kolodrubetz, D. \& Kraig, E. (1993). A panel of probes detects DNA polymorphisms in human and non-human primate isolates of a periodontal pathogen, Actinobacillus actinomycetemcomitans. Microb Patbog 14, 103-115.

Han, N., Hoover, C. I., Winkler, J. R., Ng, C. Y. \& Armitage, G. C. (1991). Identification of genomic clonal types of Actinobacillus actinomycetemcomitans by restriction endonuclease analysis. $J$ Clin Microbiol 29, 1574-1578.

Helmig, R., Uldbjerg, N., Boris, J. \& Kilian, M. (1993). Clonal analysis of Streptococcus agalactiae (GBS) isolated from infants with neonatal sepsis or meningitis, their mothers, and from healthy pregnant women. J Infect Dis 168, 904-909.

Kolodrubetz, D., Dailey, T., Ebersole, J. \& Kraig, E. (1989). Cloning and expression of the leukotoxin gene from Actinobacillus actinomycetemcomitans. Infect Immun 57, 1465-1469.

Kraig, E., Dailey, T. \& Kolodrubetz, D. (1990). Nucleotide sequence of the leukotoxin gene from Actinobacillus actinomycetemcomitans: homology to the alpha-hemolysin/leukotoxin gene family. Infect Immun 58, 920-929.

Lally, E. T., Golub, E. E., Kieba, I. R., Taichman, N. S., Rosenbloom, J., Rosenbloom, J. C., Gibson, C. W. \& Demuth, D. R. (1989a). Analysis of the Actinobacillus actinomycetemcomitans leukotoxin gene. $J$ Biol Chem 264, 15451-15456.

Lally, E. T., Kieba, I. R., Demuth, D. R., Rosenbloom, J., Golub, E. E., Taichman, N. S. \& Gibson, C. W. (1989b). Identification and expression of the Actinobacillus actinomycetemcomitans leukotoxin gene. Biochem Biophys Res Commun 159, 256-262.

Lally, E. T., Golub, E. E., Kieba, I. R., Taichman, N. S., Decker, S., Berthold, P., Gibson, C. W., Demuth, D. R. \& Rosenbloom, J. (1991). Structure and function of the $B$ and $D$ genes of the Actinobacillus actinomycetemcomitans leukotoxin complex. Microb Pathog 11, 111-121.

LeBlanc, D. J., Lee, L. N., Abu-Al-Jaibat, A. R., Sreenivasan, P. K. \& Fives-Taylor, P. M. (1993). Identification of plasmids in Actinobacillus actinomycetemcomitans and construction of intergeneric shuttle plasmids. Oral Microbiol Immunol 8, 94-99.

Loos, B. G., Dyer, D. W., Whittam, T. S. \& Selander, R. K. (1993). Genetic structure of populations of Porpbyromonas gingivalis associated with periodontitis and other oral infections. Infect Im mun 61, 204--212.

McArthur, W. P., Tsai, C.-C., Baehni, P. C., Genco, R. J. \& Taichman, N. S. (1981). Leukotoxic effects of Actinobacillus actinomycetemcomitans. Modulation by serum components. J Periodontal Res 16, 159-170.

Meyer, D. H., Sreenivasan, P. K. \& Fives-Taylor, P. M. (1991). Evidence for invasion of a human oral cell line by Actinobacillus actinomycetemcomitans. Infect Immun 59, 2719-2726.

Musser, J. M., Granoff, D. M., Pattison, P. E. \& Selander, R. K. (1985). A population genetic framework for the study of invasive diseases caused by serotype b strains of Haemophilus influenzae. Proc Natl Acad Sci US.A 82, 5078-5082.

Musser, J. M., Barenkamp, S. J., Granoff, D. M. \& Selander, R. K. (1986). Genetic relationships of serologically nontypable and serotype b strains of Haemophilus influenzae. Infect Immun 52, 183-191.

Musser, J. M., Hauser, A. R., Kim, M. H., Schlievert, P. M., Nelson, K. \& Selander, R. K. (1991). Streptococcus pyogenes causing toxic- 
shock-like syndrome and other invasive diseases: clonal diversity and pyrogenic exotoxin expression. Proc Natl Acad Sci USA 88, 2668-2672.

Olsvik, B. \& Preus, H. R. (1989). Plasmids in Actinobacillis actinomycetemcomitans strains isolated from periodontal lesions of patients with rapidly destructive periodontitis. Oral Microbiol Immunol 4, 219-221.

Page, R. C., Sims, T. J., Engel, L. D., Moncla, B. J., Bainbridge, B., Stray, J. \& Darveau, R. P. (1991). The immunodominant outer membrane antigen of Actinobacillus actinomycetemcomitans is located in the serotype-specific high-molecular-mass carbohydrate moiety of lipopolysaccharide. Infect Immun 59, 3451-3462.

Poulsen, K., Hjorth, J. P. \& Kilian, M. (1988). Limited diversity of the immunoglobulin A1 protease gene (iga) among Haemophilus infuenzae serotype b strains. Infect Immun 56, 987-992.

Preus, H. R., Olsen, I. \& Namork, E. (1987). Association between bacteriophage-infected Actinobacillus actinomycetemcomitans and rapic periodontal destruction. J Clin Periodontol 14, 245-247.

Saarela, M., Asikainen, S., Alaluusua, S., Phyälä, L., Lai, C.-H. \& Jousimies-Somer, H. (1992). Frequency and stability of mono- or poly-infection by Actinobacillus actinomycetemcomitans serotypes a, b. c, d or e. Oral Microbiol Immunol 7, 277-279.

Saarela, M., Asikainen, S., Jousimies-Somer, H., Asikainen, T., von Troil-Linden, B. \& Alaluusua, S. (1993). Hybridization patterns of Actinobacillus actinomycetemcomitans serotypes a-e detected with an rRNA gene probe. Oral Microbiol Immunol 8, 111-115.

Sambrook, J., Fritsch, E. F. \& Maniatis, T. (1989). Molecular Cloning: a Laboratory Manual, 2nd edn. Cold Spring Harbor, NY: Cold Spring Harbor Laboratory.

Selander, R. K., Caugant, D. A., Ochman, H., Musser, J. M., Gilmour, M. N. \& Whittam, T. S. (1986). Methods of multilocus enzyme electrophoresis for bacterial population genetics and systematics. Appl Environ Microbiol 51, 873-884.
Selander, R. K., Beltran, P., Smith, N. H., Helmuth, R., Rubin, F. A., Kopecko, D. J., Ferris, K., Tall, B. D., Cravioto, A. \& Musser, J. M. (1990). Evolutionary genetic relationships of clones of Salmonella serovars that cause human typhoid and other enteric fevers. Infect Immun 58, 2262-2275.

Slots, J., Reynolds, H. S. \& Genco, R. J. (1980), Actinobacillus actinomycetemcomitans in human periodontal disease : a cross-sectional microbiological investigation. Infect Immun 29, 1013-1020.

Smith, J. M., Smith, N. H., O'Rourke, M. \& Spratt, B. G. (1993). How clonal are bacteria? Proc Natl Acad Sci USA 90, 4384-4388.

Spitznagel, J., Jr, Kraig, E. \& Kolodrubetz, D. (1991). Regulation of leukotoxin in leukotoxic and nonleukotoxic strains of Actinobacillus actinomycetemcomitans. Infect Immun 59, 1394-1401.

Stevens, R. H., Hammond, B. F. \& Lai, C. H. (1982). Characterization of an inducible bacteriophage from a leukotoxic strain of Actinobacillus actinomycetemcomitans. Infect Immun 35, 343-349.

Wilson, M. E. \& Schifferle, R. E. (1991). Evidence that the serotype $\mathrm{b}$ antigenic determinant of Actinobacillus actinomycetemcomitans Y4 resides in the polysaccharide moiety of lipopolysaccharide. Infect Immun 59, 1544-1551.

Zambon, J. J., Christersson, L. A. \& Slots, J. (1983a). Actinobacillus actinomycetemcomitans in human periodontal disease: prevalence in patient groups and distribution of biotypes and serotypes within families. $J$ Periodontol 54, 707-711.

Zambon, J. J., Slots, J. \& Genco, R. J. (1983b). Serology of oral Actinobacillus actinomycetemcomitans and serotype distribution in human periodontal disease. Infect Immun 41, 19-27.

Zambon, J. J., Sunday, G. J. \& Smutko, J. S. (1990). Molecular genetic analysis of Actinobacillus actinomycetemcomitans epidemiology. J Periodontol 61, 75-80.

Received 24 November 1993; revised 28 February 1994; accepted 10 March 1994. 